\title{
KETIDAKADILAN DAN CINTA \\ DALAM NASKAH HIKAYAT NEGERI ATAS ANGIN KOLEKSI PERPUSTAKAAN NASIONAL PERANCIS
}

\author{
Silmi Nur Alfiah", Asep Yudha Wirajaya ${ }^{\mathrm{b}}$ \\ Prodi Sastra Indonesia, Fakultas Ilmu Budaya \\ Universitas Sebelas Maret
}

Jalan Ir. Sutami 36 Kentingan, Jebres, Surakarta, Jawa Tengah, Indonesia 57126.

silminuralfiah@gmail.com; asepyudha.w@gmail.com

(Diterima: 27 November 2019; Direvisi 26 April 2021; Disetujui 29 April 2021)

\begin{abstract}
Abstrak
Penelitian ini mengkaji naskah yang berjudul Hikayat Negeri Atas Angin (selanjutnya disingkat HNAA) merupakan naskah tunggal yang tersimpan di Perpustakaan Nasional Prancis, dengan nomor kode inventarisasi metadata Malayo-Polynes 56. HNAA termasuk dalam jenis cerita berbingkai dalam khazanah sastra Nusantara pada masa peralihan Hindu ke Islam. Dalam teks HNAA dikisahkan ketidakadilan seorang pemimpin atau raja yang bernama Raja Maharaja Ali. Oleh karena itu rasa cinta dan kasih sayang yang yang terlalu berlebihan kepada pihak keluarganya, Maharaja Ali tidak dapat menjalankan tugas dengan baik, yaitu sebagai seorang pemimpin yang adil bagi seluruh rakyatnya. Penelitian ini merupakan penelitian kualitatif dengan menggunakan teori kontekstualitas. Berdasarkan hasil analisis dapat diketahui bahwa memahami kebudayaan suatu bangsa yaitu kebiasaan masyarakat dan terungkapnya sejarah suatu bangsa pada masa lampau. Melalui naskah HNAA di dalamnya terkandung karakter yang seharusnya dimiliki oleh seorang pemimpin.
\end{abstract}

Kata kunci: Hikayat Negeri Atas Angin, Raja Maharaja Ali, pemimpin, ketidakadilan, dan cinta

\section{Injustice and Love in the Tale of the Land Over the Wind: Contextuality Approach}

\section{Abstract}

This study examined a manuscript entitled Hikayat Negeri Atas Angin (hereinafter abbreviated as HNAA) is a single manuscript stored in the National Library of France, with the metadata inventory code number Malayo-Polynes 56. HNAA is included in the type of story framed in the literary treasures of the Archipelago during the transition of Hinduism to Islam. In the text of HNAA is told the injustice of a leader or king named Raja Maharaja Ali. Therefore, excessive love and affection on the part of his family, Maharaja Ali could not perform his duties properly, namely as a just leader for all his people. This research is qualitative research using contextuality theory. Based on the results of the analysis can be known that understanding the culture of a nation is the habits of society and the unfolding of the history of a nation in the past. Through the HNAA script it contains characters that should be owned by a leader. Keywords: Hikayat Negeri Atas Angin, Raja Maharaja Ali, leader, injustice, and love

\section{PENDAHULUAN}

Nusantara adalah kawasan yang termasuk ke dalam bagian dari Asia Tenggara. Kawasan ini, sejak kurun waktu yang lama memiliki peradaban tinggi dan mewariskan kebudayaan kepada anak keturunannya melalui berbagai media, antara lain media tulisan yang berupa naskah-naskah. Kawasan Nusantara terbagi dalam banyak kelompok etnis yang masingmasing memiliki bentuk kebudayaan yang khas, tanpa meninggalkan sifat kekhasan kebudayaan Nusantara. Kekayaan Nusantara dibuktikan dengan jumlah koleksinya yang dewasa ini terdapat di berbagai pusat studi kebudayaan timur (Effendy, 2016).

Sayangnya, keberadaan naskahnaskah kuno yang tersebar di seluruh Nusantara ini masih belum banyak diketahui oleh masyarakat umum. Terlebih lagi, penelitian naskah-naskah kuno yang tersimpan dalam koleksi-koleksi pribadi atau kelompok masyarakat atau komunitas 
masyarakat adat tertentu masih sangat jarang dilakukan. Oleh karena itu, diperlukan upaya tersendiri untuk melakukan penyelamatan, baik dari aspek fisik naskahnya maupun aspek isi teksnya agar khazanah pemikiran nenek moyang kita yang terkandung di dalam naskah dapat digunakan sebagai alternatif solusi bagi pembangunan bangsa (Ikram, 2019; Wirajaya, Asep Yudha, 2016)

Hal itu perlu dilakukan mengingat sejarah keberaksaraan Nusantara. Misalnya Melayu dengan Pulau Panyengat (sebuah pulau kecil di Kota Tanjungpinang, Kepulauan Riau) telah dikenal sebagai salah satu pusat kegiatan sastra dan budaya yang sangat maju. Bahkan, Pulau Panyengat merupakan salah satu pusat kebudayaan diakui oleh masyarakat Nusantara dan telah resmi ditetapkan sebagai lembaga kebudayaan Melayu. Namun, masih banyak naskah-naskah Nusantara yang kini dikoleksi secara pribadi oeh masyarakat Nusantara, baik di dalam negeri maupun di mancanegara (Wirajaya, dkk., 2016)

Dalam kajian filologi, naskah merupakan salah satu sumber primer paling autentik yang dapat mendekatkan jarak antara masa lalu dan masa kini. Dalam konteksnya di Nusantara ini, naskah yang jumlahnya melimpah dalam berbagai bahasa, menjadi 'lumbung emas' yang sudah lama disadari oleh para sarjana Barat dan Eropa sejak zaman dahulu, tetapi belum maksimal dimanfaatkan oleh para pribumi sendiri hingga beberapa tahun belakangan ini. (Fathurahman, 2015)

Ketidakmampuan pribumi tersebut mengakibatkan banyaknya naskah yang tersebar di Nusantara sebagian hancur atau musnah karena faktor alam dan sebagian lagi dibawa oleh para sarjana Eropa dan Barat. Hal ini dapat dibuktikan dengan banyaknya naskah-naskah kuna Nusantara yang tersimpan di berbagai perpustakaan internasional di luar negeri. Naskah-naskah tersebut sudah diarsipkan, didigitalkan, dan dijadikan bagian dari koleksi mereka (Kurniawan, 2017; Wirajaya, 2015).

Ada satu perkembangan yang menggermbirakan dari era digitalisasi, beberapa perpustakaan di luar negeri membuka akses secara daring kepada para peminat naskah Nusantara untuk dapat melihat, membaca, dan mengunduh versi digital naskah-naskah Nusantara tersebut. Hal ini tentu akan menjadi tantangan dan peluang tersendiri bagi para calon pengkaji naskah Nusantara (Wirajaya, 2019). Salah satu naskah yang dapat diakses adalah naskah Hikayat Negeri Atas Angin (HNAA).

$H N A A$ merupakan naskah Melayu yang tersimpan dalam koleksi Perpustakaan Nasional Prancis. Naskah ini tercatat dengan nomor inventarisasi metadata Malayo-Polynes 56. Berdasarkan informasi yang tercantum dalam metadata naskah $H N A A$, diketahui bahwa ukuran halaman naskah adalah $19,3 \mathrm{~cm} \times 14,2 \mathrm{~cm}$. Adapun jumlah halaman naskah secara keseluruhan adalah 70 halaman, tetapi lembaran yang ditulisi hanya berjumlah 45 halaman. Sementara, jumlah baris tiap halaman adalah 15 baris. Secara umum, keadaan naskah HNAA masih baik, yaitu dengan warna kertas kuning kecokelat-cokelatan, dan semua tulisan yang tertera dengan tinta hitam dan merah di dalam naskah masih dapat terbaca dengan jelas. Adapun penggunaan tinta merah hanya dilakukan sebagai penanda kata-kata tumpuan awal kalimat atau paragraf, seperti "hatta", "adapun" "sebermula", dan "maka". Selain itu, diketahui pula bahwa naskah HNAA masih terjilid dengan baik dan bersampul kertas warna merah bata dan coklat (Anonim, n.d.). 
Naskah HNAA ini menceritakan tentang seorang raja di negeri atas angin yang bernama Raja Maharaja Ali yang memohon kepada tuhan untuk diberikan keturunan. Akhirnya, Raja Maharaja Ali dianugerahkan oleh Allah swt. tiga orang anak laki-laki. Pada suatu hari, seorang anak laki-lakinya yang bernama Baharama Syah suka bermain wanita yang membuat rakyat dan para menteri tidak suka. Sudah berkali-kali perkara tersebut diberitahukan kepada raja, tetapi sang raja menolak untuk menghukum anaknya sendiri. Hal itu disebabkan oleh rasa cinta dan sifat kasih sayangnya yang terlalu berlebihan kepada anaknya. Akibat dari ketidakadilan sang raja itulah, kemudian sang raja dan keluarga diusir dari istananya sendiri dan berjalan ke hutan. Dalam perjalanannya itulah, sang raja kemudian bertemu dengan Nabi Sulaiman, Nabi Daud, dan Nabi Isa. Singkat cerita, akhirnya Raja Maharaja Ali dapat kembali ke kerajaannya (Anonim, n.d.)

Dalam penelitian lainnya yang berjudul "Nilai Kepemimpinan dalam Naskah Hikayat Maharaja Ali" dari koleksi Perpustakaan Nasional Republik Indonesia (PNRI) dengan kode naskah ML. 638 A, terdapat pembelajaran untuk mencari pemimpin. Seorang tokoh pemimpin sebuah organisasi atau negara sekalipun melalui banyak pertimbangan untuk dapat memimpin sebuah pemerintahan. Nilai kepemimpinan dalam budaya Melayu sangat erat dengan ajaran agama Islam yang berpedoman pada ajaran Nabi Muhammad saw. Naskah ini masih dapat dipakai karena kondisinya yang terbaca dengan baik dan isi naskah yang masih relevan untuk digunakan hingga sekarang. (Purwanto, 2013)

Tema yang diceritakan dalam naskah ini adalah keadilan seorang raja dan kesetiaan istri. Dalam tradisi melayu jika ada seorang raja yang tidak adil namun tidak juga mengambil hak-hak rakyatnya maka tidak akan diacuhkan ataupun dihormati, tetapi berbeda halnya jika seorang raja mengganggu kehidupan rakyatnya. Melalui penelitian ini dapat diketahui bahwa cinta dalam banyak hal bersifat positif dapat juga bersifat negatif jika bertentangan dengan kewajiban moral seorang hamba dan khalifah (pemimpin) Tuhan di muka bumi. (Hadi, 2008)

Naskah HNAA merupakan naskah yang berisi tentang tokoh Maharaja Ali sebagai pemimpin. Sudah banyak naskah yang membahas tentang Maharaja Ali namun tiap naskah akan ada sedikit perbedaan kisahnya. Peneliti menggunakan naskah $H N A A$ karena menarik untuk diteliti dan mendapatkan pesan moralnya. Meskipun banyak naskah yang berjudul sama yaitu tentang Maharaja Ali, tetapi dalam naskah ini disuguhkan pesan moral yang baik mengenai sosok pemimpin yang seharusnya adil dan penuh kasih sayang kepada rakyatnya tidak hanya kepada keluarganya sendiri. Isi naskah dalam HNAA berbeda dengan cerita Maharaja Ali lainnya.

Berdasarkan analisis tersebut, pokok permasalahan yang dibahas dalam penelitian ini adalah: (1) sifat ketidakadilan seorang raja/pemimpin kepada rakyatnya; (2) sifat cinta dan kasih sayang yang benar harus dimiliki seorang raja/pemimpin. Sedangkan tujuan dari penelitian ini adalah menggambarkan kisah Maharaja Ali yang sangat mencintai keluarganya dan tidak berbuat adil kepada rakyat di negerinya sendiri.

\section{TEORI}

Kajian filologi klasik atau konvensional menjadikan teks yang siap 
baca bagi masyarakat merupakan tahapan akhir. Namun demikian, filologi klasik dianggap "kering” jika hanya berkutat pada pembenahan kesalahan tulisan. Selain itu, filolog hanya menyediakan bahan mentah untuk dikaji disiplin ilmu lain. Padahal, yang mengetahui lebih dalam teks yang disunting itu adalah filolog sendiri. Dengan demikian, sesunggunya yang lebih kompeten mengkaji edisi teks tersebut adalah si penyunting (Luthfi, 2016). Atas dasar itulah, kajian filologi dikembangkan secara kontekstual berkaitan dengan tema yang terkandung dalam teks. Hal itu dimaksudkan untuk lebih memahami keutuhan teks tersebut dalam sebuah konteks yang melahirkannya (Luthfi, 2016: 11).

Dengan demikian, konteks adalah bagian suatu uraian atau kalimat yang dapat mendukung atau menambah kejelasan makna, situasi yang ada hubungannya dengan suatu kejadian. Selain itu, kontekstual dapat juga berarti berhubungan dengan konteks (Effendy, 2016)

Jadi, konteks adalah situasi yang di dalamnya suatu peristiwa terjadi, atau situasi yang menyertai munculnya sebuah teks; sedangkan kontekstual artinya berkaitan dengan konteks tertentu. Pendekatan kontekstual yang dimaksud di sini adalah pendekatan yang mencoba menafsirkan teks HNAA berdasarkan analisis latar belakang, bahasa, sosiologi, yang berlaku di masyarakat dulu dengan perbandingan masyarakat sekarang (Solahudin, 2016, p. 3)

Secara umum, kontekstualitas filologi dibagi menjadi dua, yaitu, kontekstualisasi objektif adalah usaha kritis, analitis, dan kontekstual yang memposisikan teks pada masa itu sehingga perlu dikaji hubungan pengarang dan konteks sosiologis saat teks dilahirkan.
Seakan-akan penyunting mangalami peristiwa historis seperti yang dialami pengarang naskah. Adapun kontekstualisasi subjektif adalah usaha kritis, analitis, dan kontekstual yang memposisikan teks pada masa sekarang yang terputus dari pengarang dan masa kelahiran teks. Pemaknaan teks diserahkan sepenuhnya kepada pembaca yang sekaligus penyunting (Luthfi, 2016).

Dalam hal ini keduanya memiliki keterkaitan yang sangat erat bagi perkembangan metode filologi. Suatu teks yang diteliti dapat dihubungkan oleh masa lalu pengarang, konteks sosiologisnya, dan juga dapat ditafsirkan sendiri menurut perhatian pada zaman sekarang ini.

Dalam pembahasan teks $H N A A$ ini, digunakan metode pendekatan kontekstualitas karena sejalan dengan pengertiannya, yaitu suatu metode yang menganalisis suatu teks dalam naskah dengan mengaitkannya dengan sosiologi zaman teks itu dilahirkan, bahasa yang digunakan, dan berbagai hubungan isi teks dengan konteks yang dilahirkan.

\section{METODE}

Menururt Moelong (Moelong, 2015) Penelitian kualitatif adalah penelitian yang bermaksud untuk memahami fenomena tentang apa yang dialami oleh subjek penelitian, misalnya perilaku, persepsi, motivasi, tindakan, dan lain sebagainya secara holistik dan dengan cara deskripsi dalam bentuk kata-kata dan bahasa pada suatu konteks khusus yang alamiah dan dengan memanfaatkan berbagai metode ilmiah.

Penelitian kualitatif adalah suatu penelitian ilmiah yang bertujuan untuk memahami suatu fenomena dalam konteks sosial secara alamiah dengan mengutamakan proses interaksi komunikasi yang dalam antara peneliti dengan 
fenomena yang diteliti. Ilmiah berarti dapat dipertanggungjawabkan keabsahannya dan dapat dipercaya valid dan reliabitasnya. Konteks sosial berarti bahwa fenomena yang diteliti merupakan kesatuan antara subjek dan lingkungan sosialnya. Alamiah berarti tidak dibenarkan untuk mengubah atau memanipulasi data penelitian yang ada. Kemudian, proses interaksi komunikasi yaitu antara peneliti dan fenomena yang diteliti. (Herdyansah, 2019).

Dalam penelitian ini, naskah HNAA dibaca dan ditelaah dengan pendekatan kontekstual untuk menjawab permasalahan peneltian ini.

\section{HASIL DAN PEMBAHASAN}

Secara umum, kontekstualisasi filologis ini dibagi menjadi dua, yakni subjektif dan objektif. Kontekstualisasi objektif adalah Kehadiran teks dipandang tidak berangkat dari ruang kosong, penyunting harus memproduksi atau merekonstruksi makna sebagaimana dimaksud penulis naskah. Sedangkan, filologis kontekstual subjektif adalah usaha kritis, analitis dan kontekstual yang memposisikan teks pada masa sekarang yang terputus dari pengarang dan masa kelahiran teks. Pemaknaan dan penafsiran terhadap teks diserahkan pada pembacabaca dan penyunting (Khabibi Muhammad Luthfi, 2016)

Dalam pembahasan ini, metode pendekatan kontekstual dapat dgunakan sesuai dengan naskah HNAA yaitu pemaknaan teks tidak terlepas dari masa penulisan, artinya tidak berangkat dari ruang kosong penyunting juga harus memprodukasi makna yang terkandung dalam naskah. Naskah juga tidak terlepas dari pengarang masa lalu atau masa sekarang karena pemaknaan teks diserahkan langsung oleh pembaca/penyunting.

Karakter seorang raja atau pemimpin merupakan penentu keberhasilan suatu bangsa. Semestinya, seorang pemimpin harus memiliki sifat dan perlakuan yang baik, adil, cinta, dan kasih untuk semua orang. Tidak hanya rakyat yang harus selalu mentaati suatu peraturan, tetapi untuk semua golongan wajib mentaati peraturan yang telah dibuat. Dengan demikian, seorang raja atau pemimpin dapat diibaratkan sebagai nahkoda yang dituntut piawai untuk mencapai tujuan bersama. Dalam naskah HNAA dapat diurakan sebagai berikut.

\section{Ketidakadilan Raja Maharaja Ali}

Salah satu sifat raja yang harus dimiliki adalah sifat adil. Adil berarti sama berat, tidak berat sebelah, tidak memihak, berpegang pada kebenaran, tidak sewenang-wenang. Dalam teks HNAA, dikisahkan bahwa Raja Maharaja Ali tidak mampu memberikan keadilan kepada rakyatnya dengan memberikan hukuman kepada sang anak yang bersalah karena telah melakukan perzinahan. Berikut ini adalah kutipannya.

“...alkisah maka datanglah cetra anak raja yang tuah itu yang bernama Baharma Syah itu tiada lain kerjanya mengambil anak bini orang dan anak menteri dirusakkannya. Senantiasa orang datang persembahkan hal kepada raja maharaja ali. Maka raja itu tiada juga mau menghukumkan anaknya daripada sangat kasihnya pada anak itu. Demikianlah lakunya berapa kali orang datang mengadukan kelakuan anak raja itu. Maka tiada juga raja memerisakkan halnya orang itu. Maka segala orang pun berdatang sembah kepada menteri. Maka baharama, maka katanya segala rakyat: "ya tuanku, adapun kita ini tiada boleh duduk dalam negeri ini sebab 
aniyaya anak raja kita. Adapun patika sudah persembahkan hal patika sekalian ini kepada raja maka tiada juga raja itu menghukumkan anaknya hukum yang adil..." (Anonim, n.d., Hlm. 12)

Berdasarkan kutipan tersebut, dapat diketahui bahwa raja tidak mampu memberikan rasa keadilan kepada rakyatnya. Justru, raja dengan sengaja melakukan pembiaran terhadap perilaku anaknya yang kerap melakukan kejahatan terhadap anak bini orang anak-anak menteri. Jelas, hal tersebut menimbulkan keresahan dan ketidaknyamanan karena rakyat dan menteri merasa tidak diperlakukan secara adil.

Akhirnya, ketidakadilan Raja Maharaja Ali tersebut berdampak pula pada dirinya sendiri dan keluarganya. Hal tersebut terlihat melalui kutipan sebagai berikut.

“...kata menteri itu, jikalau demikian baiklah kita semuanya kecil besar marilah mufakat, maka kita nyahkan raja itu dari negeri ini. Setelah sudah perjanjian banyak menteri dan segala rakyat sekalian, maka kepada suatu hari maka datanglah menteri dan segala rakyat kecil dan besar kepada raja maharaja ali... "(Anonim, n.d. Hlm.13) Akibat tidak dapat berlaku adil, maka Raja Maharaja Ali dan keluarganyadiusir dari negerinya sendiri. Hal itu terjadi karena sang raja terlalu menaruh belas kasihan terhadap nasib anaknya jika dihukum. Tentu saja, tidak dapat dihadirkannya rasa keadilan bagi siapa pun akan membawa bencana bagi kehidupan secara keseluruhan. Dalam konteks cerita $H N A A$, akibat ketidakadilan tersebut membuat sang raja dan keluarganya dilengserkan dari kekuasaannya dan diusir dari kerajaannya. Hal ini dapat dipahami karena sebagai seorang pemimpin sudah seharusnya dia mampu bersikap yang adil dan menegakkan peraturan yang telah ada. Manakala seorang raja tidak lagi mampu menghadirkan keadilan dalam keputusan dan kekuasaannya, maka sebenarnya ia telah "gagal" sebagai seorang pemimpin sejati. Karena raja sebenarnya adalah wakil Tuhan di muka bumi, maka ia harus mampu mencerminkan sifat Tuhan Yang Maha Adil. Selain itu, manakala seoarng pemimpin melakukan pembiaran terhadap ketidakadilan, sesungguhnya ia secara sadar telah mengundang murka Tuhan untuk didatangkan dengan sesegera mungkin (Wiranta, Murtini, \& Wirajaya, 2019).

Kemudian, dalam cerita selanjutnya Raja Sulaiman berbeda dengan Raja Maharaja Ali mengenai hukuman yang diberikan kepada anaknya yang telah berbuat kejahatan. Berikut kutipannya:

"...maka Raja Sulaiman pun persembahkan surat itu kepada ayahnya. Maka Nabi Daud pun membaca surat itu. Maka lalu ia mengerakkan kepalanya. Maka kata Nabi Daud kepada anaknya, engkaulah duduk dalam pagar istanaku menggantikan aku dan anakkulah menghukumkan segala orang dalam negeri ini mana hukum anakku itu hukumkan dengan yang adil. Adapun amaranya Nabi Sulaiman naik raja itu baru tujuh tahun lamanya dengan hukum baginya dan qodhi dan khatib dan imam dan bilal empat orang itu dicukurkannya rambutnya. Maka ditaruh harang dan kafar --- mukanya. Maka kemudian, maka disuruh kelilingkan dalam negeri tiga kali. Sudah itu, maka disuruh buangkan kepada negeri yang lain demikianlah hukum Raja Sulaiman itu.." (Anonim, n.d.Hlm.34)

Raja Sulaiman menjadi seorang raja yang adil di negerinya. Beliau tidak segan-segan menghukum anaknya sendiri yang berbuat kejahatan. Hal itu membuktikan peran seorang raja sekaligus nabi yang penuh keadilan. Rasa cinta kepada anaknya tidak membuat beliau lupa untuk menegakkan 
keadilan di negeri. Begitu pula apabila segala rakyat yang telah berbuat tidak adil, maka akan diberikan hukuman yang pantas.

Selanjutnya, diceritakan seorang raja yang bernama Raja Sardala yang berbuat aniaya kepada Putri Hinan. Berikut ini adalah kutipannya:

“...Alkisah maka datanglah cetra putri hinan ister Raja Maharaja Ali yang dianiyaya oleh Raja Sardala. Adapun raja itu hendak ditawari kepada putri itu, maka kata putri hinan, "Hai Raja Sardala, dengarkan dahulu kala suatu citra tatkala zaman Nabi Allah ada raja bernama..."(Anonim, n.d.Hlm.21)

Raja Sardala diceritakan tidak berbuat adil kepada Putri Hinan, yaitu isteri Raja Maharaja Ali itu sendiri. Raja Sardala merupakan bukti seorang raja yang suka berbuat aniyaya kepada rakyatnya sendiri. Di akhir kisahnya, Raja Sardala memohon ampun dan memberi hormat kepada Raja Maharaja Ali karena perbuatannya yang menganiaya kepada Putri Hinan.

\section{Cinta seorang Raja}

Dalam teks $H N A A$ ini dikisahkan bahwa Raja Maharaja Ali memiliki sifat kasih sayang dengan cara yang salah. Akibatnya, dia tidak mau menghukum anaknya sendiri yang telah berbuat kejahataan kepada rakyatnya. Berikut adalah kutipannya:

“...raja itu tiada juga mau menghukumkan anaknya daripada sangat kasihnya pada anak itu. Demikianlah lakunya berapa kali orang datang mengadukan kelakuan anak raja itu.." (Anonim, n.d.Hlm. 12)

Berdasarkan kutipan di atas, dapat diketahui bahwa Raja Maharaja Ali tidak tega menjatuhkan hukuman kepada anaknya. Semestinya, seorang pemimpin yang baik mampu bersikap adil terhadap hukum yang berlaku dan tidak membiarkan sifat kasihnya tersebut menghalang-halangi ditegakkannya keadilan (Wirajaya, 2017).
Kemudian, dalam teks selanjutnya dijelaskan bahwa ada seorang raja yang setiap hari bersedekah kepada rakyatnya yang fakir dan miskin. Berikut ini kutipannya:

“...maka berapa lamanya berjalan sampailah kepada suatu negeri --namanya negeri itu kepada waktu maghrib, maka Raja Ali pun pikir di dalam hatinya --- aku sekarang membawa diriku, maka ia pun lalu ke masjid. Maka Raja Ali pun bertemu ia dengan bilal dalam masjid itu. Maka Raja Ali pun memberi salam. Maka Bilal pun menyahuti salam raja ali itu. Maka kata Raja Ali, "Hai Bilal adakah raja negeri ini memberi sedekah segala fakir dan miskin? Maka bilal pun berkata adalah senantiasa pagi-pagi hari raja itu memberi sedekah pada segala fakir dan miskin..."(Anonim, n.d.Hlm.7)

Dalam kutipan tersebut, diceritakan bahwa Raja Maharaja Ali bertanya kepada seseorang yang ada di dalam masjid, yaitu Bilal, apakah ada raja di negeri ini yang memberi sedekah kepada fakir dan miskin? Bilal menjawab bahwasanya ada seorang raja yang di pagi hari selalu memberi sedekah kepada rakyatnya yang fakir dan miskin. Hal ini berarti bahwa seorang raja atau pemimpin harus memiliki rasa cinta kepada rakyatnya, salah satunya adalah dengan memberikan sedekah kepada fakir dan miskin. Dengan demikian, seorang raja juga harus tetap memperhatikan keadaan rakyatnya.

\section{PENUTUP}

Dengan dilakukannya kajian
terhadap naskah Nusantara secara kontekstual, didapatkan mutiara-mutiara kehidupan yang dapat digunakan sebagai alternatif solusi bagi kehidupan bermasyarakat dan bernegara, baik di masa 
sekarang maupun di masa-masa yang akan datang. Jadi, dalam sebuah teks, selalu ada asas kesinambungan antara kehidupan generasi dulu, generasi sekarang, dan generasi masa depan.

Kedua, seorang pemimpin sudah seharusnya mampu bersikap adil dan menegakkan hukum. Manakala seorang raja sudah tidak lagi mampu menghadirkan keadilan dalam setiap keputusan dan kekuasaannya, sebenarnya ia telah "gagal" sebagai seorang pemimpin sejati. Raja dipercaya wakil Tuhan di muka bumi, ia harus mampu mencerminkan sifat Tuhan Yang Maha Adil. Selain itu, manakala seoarng pemimpin melakukan pembiaran terhadap ketidakadilan, sesungguhnya ia telah mengundang murka Tuhan.

Ketiga, rasa cinta dan kasih sayang Raja Maharaja Ali terhadap anaknya yang berlebihan membuat dia merasa tidak tega untuk menjatuhkan hukuman kepada sang anaknya. Akibatnya, Raja Maharaja Ali diturunkan dari tahta. Dia beserta keluarganya diusir.

Keempat, seorang raja atau pemimpin memiliki rasa cinta kasih kepada seluruh rakyatnya. Hal tersebut dapat diwujudkan melalui sedekah kepada fakir dan miskin. Dengan demikian, seorang raja harus senantiasa memperhatikan keadaan rakyatnya. Apabila ada rakyat yang membutuhkan bantuan, ia hadir sebagai "pelayan" yang baik.

\section{DAFTAR PUSTAKA}

Anonim. (n.d.). Malayo-Polynesia 56. Prancis: Bibliotheque National of France.

Herdyansah, H. (2019). Metode Penelitian Kualitatif untuk Ilmu-Ilmu Sosial: Perspektif Konvensional dan

Kontemporer. Retrieved from http://www.penerbitsalemba.com Ikram, A. (2019). Pengantar Penelitian.
Jakarta: Masyarakat Pernaskahan Nusantara (MANASSA).

Khabibi Muhammad Luthfi. (2016). Kontekstualisasi Filologi Dalam Teks-Teks Islam Nusantara. Jurnal Kebudayaan Islam. https://doi.org/10.24090/ibda.v14i1.5 23

Kurniawan, B. (2017). Filologi Indonesia sebagai Metode dan Studi Sastra Melayu Klasik.

Moelong, L. J. (2015). Metode Penelitian Kualitatif. Bandung: Remaja Rosdakarya.

Muhadjir Effendy, D. (2016). Kamus Besar Bahasa Indonesia Jilid V. Jakarta: Kementerian Pendidikan dan Kebudayaan.

oman fathurahman. (2015). Filologi Indonesia.

Purwanto, D. (2013). Nilai Kepemimpinan Hikayat Maharaja Ali. PNRI.

Solahudin, M. (2016). Pendekatan Tekstual dan Kontekstual dalam Penafsiran Al-Qur'an. 2(Desember), 115-130.

W, A. H. (2008). Keadilan dan Cinta, dalam Hikayat Maharaja Ali. 5-7.

Wirajaya, Asep Yudha, dkk. (2016). Menelusuri Manuskrip di Tanah Jawa. Surakarta: Garengpung Publisher.

Wirajaya, A. Y. (2015). Tekstologi: Sebuah Pengantar. Surakarta: Awan Pustaka.

Wirajaya, A. Y. (2017). Cinta, Komitmen, dan Kehormatan dalam Cerpen "Bisma" Karya Putu Wijaya. Haluan Sastra Budaya. https://doi.org/10.20961/hsb.v33i1.42 46

Wirajaya, A. Y. (2019). Estetika Puitik Kesusastraan Melayu Klasik. Surakarta: Oase Pustaka.

Wiranta, W., Murtini, M., \& Wirajaya, A. Y. (2019). Gagasan Kematian dan Ketuhanan dalam Sajak-Sajak Abdul Hadi W.M. Haluan Sastra Budaya. https://doi.org/10.20961/hsb.v3i1.282 68 
Silmi Nur Alfiah ${ }^{\mathrm{a}}$, Asep Yudha Wirajaya ${ }^{\mathrm{b}}:$ Ketidakadilan dan Cinta dalam Naskah Hikayat Negeri Atas Angin Koleksi Perpustakaan Nasional Perancis 